RUNNNING HEAD: Back to SA school

\title{
Title: Back to SA school: contrasting three approaches to situation awareness in
}

\section{the cockpit.}

\author{
Linda. J. Sorensen ${ }^{\mathrm{a}^{*}}$, Neville A. Stanton ${ }^{\mathrm{a}}$ and Adrian. P. Banks ${ }^{\mathrm{b}}$ \\ ${ }^{a}$ Transportation Research Group, School of Civil Engineering and the Environment, University of \\ Southampton, Highfield, Southampton SO17 1BJ, UK; ${ }^{b}$ Department of Psychology, University of \\ Surrey, Guilford, GU2 7XH, UK
}

\section{ADDRESS FOR CORRESPONDENCE}

Linda J. Sorensen, Transportation Research Group, School of Civil Engineering, University of Southampton, Southampton, SO17 1BJ, UK.

Email: 1.j.sorensen@ soton.ac.uk 


\begin{abstract}
Situational awareness has received considerable attention in recent years and significant theoretical advances have been made. The advances to date can be categorised in three main schools of thought: psychological, engineering and systems ergonomics schools. We use the perspectives of the three schools to analyse the descent and approach of a McDonnell Douglas MD-80 series described by Hutchins (1995a). We discuss the theoretical contributions of the three schools to the understanding of SA and apply these to the analysis of the MD-80's descent and approach. Finally, we discuss how the different views advocated by the three schools give rise to different approaches to support SA. We argue that while the psychological and engineering approaches each give valuable insight into the phenomenon neither give a complete explanation of SA. We therefore dispute that only the systems ergonomics perspective, in combining the individual, artefacts in the environment and interaction between these, offer a full explanation.
\end{abstract}

Keywords: situation awareness, distributed cognition, teams, cockpit, sociotechnical systems 


\section{Introduction}

There is a growing body of literature calling for a more complete development of the theoretical foundation of SA (Burns, Skraaning, Jamieson, Lau, Kwok, Welch and Andersen, 2008; Rousseau, Tremblay and Breton, 2004). A number of studies have been conducted to identify the characteristics of SA and understand how it can be enhanced (Patrick and James, 2004; Patrick, James, Ahmed and Halliday, 2006; Patrick and Ahmed, 2007). Patrick and Morgan (2010) discuss the developments in this area to date in a comprehensive review, as do Salmon, Stanton, Walker, Baber, Jenkins, McMaster and Young (2008). Endsley, Bolté and Jones (2003) have found that the way in which information is presented to the operator through an interface influences SA by determining how much information can be processed in a limited space of time. Advances have been achieved in terms of understanding the phenomenon of SA, how it manifests itself across a range of work contexts and how it can be measured, although as of yet there is no consensus in the field. Similarly several authors have encouraged the design of systems to support SA of different users through a SA requirements analysis, rather than an overview analysis of generic roles (Endsley et al., 2003; Salmon, Stanton, Walker, Jenkins and Rafferty, 2010; Salmon, Stanton, Walker and Jenkins, 2009b).

This principle is not often adhered to (Salmon et al., 2009b). Rather, systems appear to be designed without an understanding of what information is needed by whom and how it will be used by different actors (Salmon et al., 2009b). Indeed, there are few guidelines available to inform the design of systems or displays to support the creation and maintenance of SA in teams (Sonnenwald and Pierce, 2000). A recent paper by Stanton, Salmon, Walker and Jenkins (2010) argues that there are three main schools of thought considering the phenomenon of SA; the psychological, the engineering and the systems ergonomics school. We believe the lack of appropriate guidelines for design to support SA is caused by the fragmented understanding of SA as advocated by the psychological and engineering schools respectively. Hence, we take the view, as Stanton et al. (2010) that SA is best understood as 
the interaction between people and their environment and artefacts within it as proposed by the systems ergonomics approach. As such, support for SA is required at a systems level and must take a threeangular approach to design; accounting for the individual, the environment, and the artefacts as well as the interaction that emerges between them. Endsley et al. (2003) seek to encourage this in the design eight guidelines set out in their book such as presenting level 2 information directly to the operator ( $p$. 83). Although these guidelines are useful they fall foul of continuing the separation of individual agents and artefacts such as displays. Such separation amounts to 'thinking in silos' and leaves out the interaction between the agent and the artefacts in the world from the equation. In our opinion it is the interaction which should be the focus of attention for design efforts to support SA.

This review will consider the theoretical underpinnings of SA from the advances in the three schools of thought and highlight how this literature addresses the role of displays in enhancing and supporting SA. Through an analysis of two pilot's interaction with instruments in a cockpit and each other we will show how the three schools of thought lead to fundamentally different suggestions for design (Hutchins, 1995a).

First, we briefly discuss the theoretical foundations of the three schools; second, we consider the literature which directly addresses display design as relevant for SA; third, we analyse an aircrafts process of descent and approach from the perspective of the three schools to ascertain the design implication of each; and finally we suggest future directions for display design aimed at supporting SA.

\section{Setting the scene for SA}

Attempts at defining situation awareness have given rise to a variety of views. Stanton et al. (2010) categorise these broadly into three schools of thought. They firstly describe the psychological school of thought whereby SA is seen as a psychological phenomenon which resides entirely in the agent's mind. 
Secondly, they present the engineering school of thought who argues that SA resides in the world, and finally, the third, systems ergonomics, approach in which SA is considered as an emergent property arising from an agent's interaction with their environment (Stanton et al., 2010; Stanton, Stewart, Harris, Houghton, Baber, McMaster, Salmon, Hoyle, Walker, Young, Linsell, Dymott and Green, 2006). This final school of thought sees SA as distributed cognition. Hence, the systems ergonomics approach does not separate the notion that SA resides in the mind from the world but rather sees the two as interdependent. This paper builds on the discussion of the three theoretical positions presented by Stanton et al. (2010). We argue that each school of though give rise to different explanations of SA related activity and that these consequently give rise to different ways of designing for and supporting SA. Indeed, they also give rise to different approaches to measurement of SA, a topic which has been covered in detail elsewhere (see for instance Salmon, Stanton, Walker and Jenkins, 2009a).

In our opinion, establishing a boundary for analysis of SA around either people or objects in the world artificially divides up what is really a system, and that analysis of either alone does not adequately explain the phenomenon of SA nor does it produce appropriate support. Both the psychological and the engineering schools have value, however, and in the following we contrast the contributions of these perspectives with that of systems ergonomics.

\subsection{SA as a psychological phenomena}

The psychological school of thought considers SA as an individual characteristic, contained within the mind of an operator (Stanton et al., 2010). Endlsey's (1995) three-level model has received most interest within this approach. Endsley (1995) state that SA is:

\footnotetext{
"the perception of the elements in the environment within a volume of time and space, the comprehension of their meaning, and the projection of their status in the near future (p. 5)".
} 
As such, SA is perceived to consist of three separate levels, perception, comprehension, and projection respectively (Endsley, 1995). Through piecing together the data inherent in the situation (perception) and understanding it (comprehension) the individual can make assumptions about the future (projection) and act accordingly. Endsley et al. (2003) argues that without a sound development of level 1 and level 2 the individual cannot achieve level 3 SA.

Endsley's (1995) definition is often favoured in the literature due to its precise levels which allows for precise measurement when one thinks of SA as three distinct and separate levels. This model therefore offers an uncomplicated explanation for SA. It is, however, not without contention. Literature in the expert research domain for instance reveals that expert decision makers have what can be considered to be SA, without being able to explain what elements of a situation they perceive to build their understanding of the situation (Klein, 1998). For these experts it is not possible to divide their SA into the three levels in a meaningful way. The model does not explain situations where SA is a continuous process, however, nor does it usefully extend to explaining team SA. Team SA is presented as shared SA where individual team members share the same SA requirements. Although it is tempting to add individual team members' SA together to provide a representation of team SA it has been argued widely that team SA is more than the sum of its parts (Salas, Prince, Baker and Schrestja, 1995; Masys, 2005; Salmon et al., 2008; Stanton, Salmon, Walker and Jenkins, 2009).

This approach emphasise the psychological qualities of the individual as imperative to achieve SA, such as cognitive capabilities. Sarter and Woods (1995), for instance consider SA as a variety of cognitive processing activities that are critical to dynamic performance. The individual develops a mental theory of the world that aids conceptualisation of how elements are to be understood, that is to say 'are explained', and how future states can be predicted (Banbury, Croft, Macken and Jones, 2004). Bedny and Meister (1999) argue that SA phenomena can only be understood as part of cognitive activity that is intensely dynamic. Similarly Artman (2000) refer to SA as 'active construction of a 
situation model'. This emphasises the individual as being an active mediator in developing and maintaining SA.

Given the above the position taken by advocates of the psychological school of thought is that several cognitive processes underlie the development of SA, and indeed the ability to maintain SA is challenged by limitations in cognitive processing (Endsley, 1999). Most important of these are attention and memory, schemata, mental models, goal-driven processing and experience. The function of cognitive factors in achieving SA, and their limitations, have been adequately described elsewhere (e.g. Endsley, 1995; 1999; 2000; Banks and Millward, in press).

Below we present the engineering approach which contrary to the above place the emphasis on the environment.

\subsection{SA as situated in the world}

The engineering school of thought asserts that SA resides in physical phenomena (Stanton et al., 2010). This is evident in the way designers and lay people discuss artefacts in the environment as 'having' SA. These views are in stark contrast to the views held by the psychological approach in that it is the artefact itself that is the holder of SA, and not the individual. Jenkins, Stanton, Salmon, Walker and Young (2008) found that military helicopter pilots refer to their displays as containing their SA. Before commencing flight the pilots are required to mark their route on a display within the cockpit. These are visual references such as symbols for rivers, power lines and churches. Jenkins et al. (2008) found that it is these visual references the pilots refer to as their SA.

Similarly engineers and operators talk of 'setting SA' in instruments and displays. They ensure the technical equipment is set to 'take care of' SA so that they do not have to expend effort to ensure that SA is adequate while performing their task. Instead, they trust the settings on the instrument to alert them when relevant changes in the environment occur. Hence, the pilots look for incongruity between the visual references and the environment outside of the cockpit as they handle the vehicle 
(Stanton et al., 2010; Jenkins et al., 2008). The individual is involved, not as the driver of SA related activity, but as the recipient of SA relevant information.

Traditional design methods and principles which address physical and perceptual characteristics of system components align with this view. A desire to design systems and technologies that counter the limitations of the fallible human remains strong in the engineering domain. In contrast to the two approaches described above the following section presents an approach to SA which does not separate the individual and its environment but rather sees SA as the interaction between these.

\subsection{SA as an emergent property}

The systems ergonomics school takes a systems approach to the study of SA. This perspective is influenced by distributed cognition (Hutchins, 1995a, b) and sociotechnical theory (Walker et al., 2009a). Stanton et al. (2006) proposed a theory of distributed SA which consists of four theoretical concepts: schema theory, genotype and phenotype schema, perceptual cycle model of cognition, and the distributed cognition approach. This model takes a systems approach to SA and considers SA as an emergent property of collaborative systems (Salmon et al., 2008; 2009b). Distributed SA, according to Salmon et al. (2008) is based on:

\footnotetext{
'the notion that in order to understand behaviour in complex systems it is more useful to study the interactions between parts in the system and the resultant emerging behaviour rather than the parts themselves' (p.369).
}

They further explain that people and artefacts comprising a system together form a "joint cognitive system" (Hollnagel, 2001) and those cognitive processes emerge from and are distributed across this system (Salmon et al., 2008). That means that cognition is achieved through coordination between 
system units, and that awareness is distributed across human and technological agents involved in collaborative activity (Salmon et al., 2008; 2009b; 2010). An artefact, such as a display, may contain 'awareness' for a specific task such as speed or temperature whereas the individual retains the 'awareness' of when to apply this information. In this way the artefact offloads the individual of the need to have awareness for the speed or temperature element of the system. This example also highlights the point made by Salmon et al. $(2008,2009 b ; 2010)$ that cognition is achieved through coordination as it is only when the individual engages with the artefacts in the environment that complete awareness is achieved.

Stanton et al. (2006) suggest that individual SA represent the state of the individual's perceptual cycle. Similarly, Smith and Hancock (1995) draw on Neisser's (1976) model in explaining how SA works. They argue that information and action flow continuously around the cycle and;

\footnotetext{
'the environment informs the agent, modifying its knowledge. Knowledge directs the agent's activity in the environment. That activity samples and perhaps anticipates or alters the environment, which in turn informs the agent' (p.141)
}

Stanton et al. (2006) do not discount the individual's importance to SA but they contend that the individual is only one part of the explanation. They explain that an individual possess genotype schemata that are triggered by the task relevant nature of task performance (Salmon et al., 2009b). During task performance the phenotype schema is brought to the fore in the ensuing interaction between the people, the world and artefacts (Salmon et al., 2009b).

Rather than SA being shared among team members Stanton et al. (2006) considers team members to possess unique but compatible portions of awareness. Compatible awareness holds distributed systems together (Stanton et al., 2006; 2009; Salmon et al., 2009b; 2010). Agents within collaborative systems enhance each other's awareness through SA transactions, such as exchange of SA relevant information (Salmon et al., 2009b). Both parties are using the information for their own 
ends, integrated into their own schemata, and interpreted individually in light of their own tasks and goals (Salmon et al., 2008; 2009b). Thus, SA in distributed teams is enhanced through transaction, rather than being shared, and each agents SA is updated via SA transactions (Salmon et al., 2009b). According to Stanton et al. (2006) distributed SA can be defined as:

‘activated knowledge for a specific task, at a specific time within a system’ (p. 1291).

This means that information held by the system becomes active at different points in time based on the goals and activities being performed and their requirements (Salmon et al., 2008). Each individual holds different SA for the same situation, depending on his or her activities and goals (Salmon et al., 2008). In a similar vein Banks and Millward (in press) argue that a mental model need not be contained within a single individual; rather it may be distributed in a group. Each person therefore holds part of the mental model (Banks and Millward, in press). The connections between the different parts of the model are maintained where necessary, e.g. by communication and interaction. Communication can function as one form of SA transaction.

The distributed SA model therefore transcends the fragmented views offered by the psychological and the engineering approaches by providing the means to view:

'the system as a whole, through a consideration of the information held by the artefacts and people and the way in which they interact' (Stanton et al., 2010, p.5).

In the following we consider the description of the descent and approach process of a McDonnell Douglas, MD-80, as presented by Hutchins (1995a) through the 'eyes' of the three main schools of thought. This example was chosen as a means of theoretical analysis as it allows for a consideration of each school's main arguments. The aim of this analysis is not only to show the differences of the three stances but also to indicate the implications of each for consideration of SA related design. 


\section{Distributed cognition in the cockpit}

Hutchins (1995a) details the process of an aircrafts descent and approach for landing in his discussion of distributed cognition in the cockpit. This article was influential to the development of the Distributed SA model within the system ergonomics approach. The process is presented in an Operator Sequence Diagram (OSD) which is used to "graphically describe activity and any interaction between agents in a network" (Stanton, Salmon, Walker, Baber and Jenkins, 2005: 115). The OSD which was created is sectioned chronologically into four parts here and was validated by a 51 year old commercial aircraft pilot with 32 years of experience flying the MD-80, among other aircrafts. See table 1 for the OSD key.

The process of approach and descent is divided into four phases. In the first phase the landing data is prepared, as can be seen in figure 1 . The PNF checks the aircraft weight on the gross weight display and selects the correct speed card from the speed card booklet, as indicated by the aircraft weight. The selected speed card is then placed on the airspeed indicator (ASI) for future reference.

\section{Figure 1 here.}

In the second phase, represented in figure 2, the speed bugs are set on the airspeed indicator next to the values on the speed card that are most important to the descent.

Figure 2 here.

Firstly, the PNF takes the speed card previously selected, and at the 227 knots, nil flap and slat extension, combines this with the speed card and moves the card onto the ASI. The PNF then moves on to the next speed and place a speed bug on the ASI by the 177 knots mark, nil flaps and full slats extension. This step is repeated for a third speed where the speed bug is set by the 152 knots mark and 
for $15^{\circ}$ flap extension with fully extended slats. In the final step the PNF places a speed bug on the ASI by 128 knots with $40^{\circ}$ and full slat extension. This completes the process of setting speed bugs. An example of an ASI with speed bugs set can be seen in figure 3.

Figure 3 here.

In phase three, as can be seen in figure 4, the speed card and speed bug settings are cross-checked by the two pilots. The PNF consults the speed card for its settings and calls these out to the Pilot Flying (PF). The PF in turn checks the values on the speed card, then the speed bugs, and reads these back to the PNF. The PF then use the speed bug settings to configure the flap and slats settings according to the values indicated on the speed card. This completes the cross-check.

Figure 4 here.

The fourth phase, the descent and final approach, represents how the PNF and the PF reduce the aircraft speed and altitude as they descend for landing, a represented in figure 5. The PNF checks the altitude indicator and when it is at 10000 feet he or she calls this value out to the PF who considers the value and reduces the speed according to the values set on the speed card, firstly to 227 knots. The PF moves the throttle and waits for the needle on the ASI to reach the desired speed bug. The speed is used to select flap and slat setting, as predetermined on the speed card, in this case no changes are required. The PF nonetheless calls out the labels for the flap and slat settings to the PNF. The PNF monitors the altitude indicator and when this reads 7000 feet calls out the value to the PF who then considers the altitude value against the necessary speed on the speed card and reduces the speed to 177 knots by moving the throttle. When the needle on the ASI reaches the next speed bug the PF calls the value out to the PNF along with the required flap and slat settings, in this case fully extended slats but no 
extension to the flaps. The PNF adjusts the positions of the flaps and slats to that effect and resumes monitoring of the altitude. As the altitude reaches 1000 feet the PNF calls this out to the PF who once again consider the value against speed and commence reduction of speed to 152 knots by moving the throttle. Once the needle has reached the speed bug at 152 knots the PF calls out the label for flaps extended to $15^{\circ}$ and slats fully extended to the PNF who adjusts the flap and slat handle accordingly. When the altitude is at 500 feet the PNF calls the value out to the PF who determines the right speed reduction, 128 knots, and moves the throttle. When the needle is by the speed bug at 128 knots the PF calls out the required flap and slat settings which are set by the PNF to $40^{\circ}$ flap extension and full slat extension. This completes the flap and slat setting for the descent and final approach.

Figure 5 here.

Below we analyse the process of descent and approach from the three schools of thought; firstly in terms of the psychological school of thought.

\subsection{Psychological approach to SA}

Figure 1 shows how the pilot not flying (PNF) prepares the landing data. The view advocated by the psychological approach suggests that SA is held in the mind of the individual operator. As such the PNF is required to develop a mental model of the correct speed in conjunction with the current aircraft weight, and must remember these crucial pieces of information to achieve SA. When applying Endsley's (1995) framework to the process portrayed, the displayed aircraft weight provides the elements, or data, in the environment which is perceived. This is level $1 \mathrm{SA}$ of the model. The correct selection of a speed card allows the PNF to comprehend the relevance of the data perceived in relation to the task of landing the aircraft. This is level 2 SA. Subsequently, the mental model formed gives 
opportunity to appropriately project future system changes and what actions will be required by the PNF in order to safely descend for landing. In other words, the PNF projects what appropriate reductions of speed should take place in order to comply with aviation safety guidelines.

Similarly if we consider figure 2 the process of setting speed bugs on the speed card continues to inform the mental model created and strengthens the PNF's ability to project appropriate speed for descent, approach and ultimately, landing. Consequently advocates of the psychological approach speak of individuals as 'having' SA (Sarter and Woods, 1991; Endsley, 1995; 1999). According to this view the PNF 'has' SA in part 1, 2, 3 and 4 of the descent and approach process, whereas the PF 'has' SA for the speed cards only in part 3.

Within the psychological approach, team SA is explained as 'the degree to which every team member possesses the situation awareness required for his or her responsibilities' (Endsley, 1995, p.31). An important aspect of team SA is shared SA (Endsley and Jones, 2001). According to Endsley and Jones shared SA refers to the level of overlap in common SA elements between team members, SA can be shared when team members perform tasks which have the same SA requirements; however, where team members perform individual tasks their SA remains individual. Intuitively one might assume that the SA requirements for the PF and the PNF would be largely similar, however, when studying figure 4 in detail it is clear that the only aspect of the task which is shared is verifying the speed card values.

Contrary to the notion of SA as residing within the mind of an individual, as indicated above, the engineering school places the emphasis on the artefacts present in the cockpit. Below we use the engineering approach to analyse the process of descent and approach.

\subsection{Engineering approach to $S A$}

When we take an engineering approach to SA we find that in the process described by Hutchins (1995a) that which is of relevance to SA are the gross weight display, speed card, airspeed indicator, 
speed bugs, flaps and slats and altitude indicator. Each artefact contains vital SA information, and arguably they present information in the form in which it is being used, hence as described in Stanton et al. (2010) the artefacts displays SA directly. The Environmental Systems Research Institute (ESRI, 2008) states that SA is

'achieved by integrating technologies to provide users with access to information based on their circumstances (p.2).'

As such, when the PNF has selected the speed card indicated by the aircrafts weight, placed the bugs aligned with the relevant speeds, and placed this on the airspeed indicator it is the airspeed indicator which 'has' SA. This is supported by Ackerman (1998) who describes artefacts as bringing SA information to individuals, and by DeMeis (1997) who present technologies as containing SA (as cited in Stanton et al., 2010).

While the above does not discount the individuals part in the process of landing the aircraft the role of the individual is here not to achieve SA but to receive SA from the artefacts. When the aircraft reaches descent and final approach, see figure 5, the airspeed indicator with the assembled speed card and speed bugs direct the pilot flying (PF) and PNF in reducing the speed with the throttle and adjusting the flaps and slats according to the present altitude. This can be taken to support the view that it is the artefacts which holds SA, not the pilots. They are following a prescribed pattern of behaviour in accordance with the instrument readings.

In our opinion the psychological and the engineering school of thought both contain valuable contributions to understanding SA; however, considering the individual and artefacts in isolation does not adequately explain the phenomenon. In contrast the systems ergonomics approach takes a holistic approach to explain SA and consider the interaction between the individual, the artefacts and the context within which they exist. 


\subsection{Systems ergonomics approach to SA}

Stanton et al (2006) argue, as does Salmon et al (2008), that each agent within a system plays a critical role in the development and maintenance of other agent's SA. Figure 5 shows how the process of descent and approach is distributed between the PNF, PF and the artefacts in the cockpit. Neither pilot alone, nor artefacts, holds adequate SA to safely land the aircraft. Smith and Hancock (1995) argue convincingly that SA does not reside in the person's mind or in the world but through the person's interaction with the world. Hutchins (1995a) explains that we can directly observe the many representations in use, which are inside the cockpit, yet still remains outside the heads of the pilots. These thoughts are founded on the distributed cognition theory which considers that joint cognitive systems comprise the people in the system and the artefacts they use (Salmon et al., 2008). Artman and Garbis (1998) assert that cognition, and therefore SA, is achieved through coordination between elements of the system. The cockpit should therefore be analysed as a whole, as a distributed system. Indeed, Hutchins (1995a) argues that memory for the speeds and the accompanying actions required by each speed to ensure safe descent is not contained by the pilots. Rather the pilots utilise the artefacts to store memory for the speed in the environment and draw on these when they are required. Memory for speed is therefore distributed between the two pilots and the artefacts in the cockpit. Hutchins (1995a) emphasise the interaction of the people with each other and the physical structures in the environment as the fundamental point of inquiry to understand cognition in complex environments. This does not discount the individual but places the individual rightly into the wider context he or she acts within.

Similarly, Stanton et al. (2006) argue that SA emerges from the interaction of people, artefacts and their environment. The pilots request and receive information from each other while also interacting with the artefacts, initially manually when setting the speed card and speed bugs and later as visual representations guiding their actions. We contend that the cross-check activity described in figure 3 can be explained, not as an expression of shared SA, but as SA transactions. The PF and the PNF exchange SA relevant information with regards to the speed card and bug settings to ensure the 
correct values have been selected. During final approach, as represented in figure 5, the PNF will call out changes in altitude which prompts the PF to push the throttle to reduce speed and call out the flap and slat settings appropriate when the required speed is reached. The flap and slat settings are then manually set by the PNF. This interdependent process shows that the PF is not aware of altitude or flap and slat handling, while the PNF is not aware at this point of the speed card or speed bugs or the throttle. The interdependence reflects the compatible nature of SA. Rather than being shared, which would suggest that the pilots have identical SA, it is clear that the pilots hold different but compatible SA. The PF is not required to hold exact awareness of altitude or flap and slat handling as he or she is not directly dealing with these, however, the PF is fundamentally aware of the importance of these to the approach. In turn the PNF, while not being aware of the throttle or the speed card for the purpose of approach is aware of the PF's handling of these. Both develop SA which is different but compatible with the other (Stanton et al., 2006).

Stanton et al. (2010) argue that compatibility binds socio-technical systems together. When presented with the same information people will have different representations of it. This is because the information will be linked in different ways with other information to produce schema for each individual (Stanton et al, 2010). The above show that ownership of SA is not held in the world or within the minds of people but is held by the system as an emergent property of its subsystems interactions.

In the analysis above we have considered the final phases of flight as described by Hutchins (1995a) from the perspectives of the three main schools of thought on SA. A summary of the analysis is presented in table 2, 3, 4 and 5 below.

Table 2, 3, 4 and 5 here. 
The three perspectives on SA consequently give rise to different principles for design to support SA; in the following we highlight these differences.

\section{Discussion}

This paper has analysed the process of descent and approach using the three main schools of SA to highlight the ways in which SA is explained. We have argued that SA is best understood as the interaction between people, artefacts and their environment. SA therefore emerges from this interaction. As such SA is a distributed property, not fully contained within either the individual or the environment, which emerges from interaction (Stanton et al., 2006; 2010). Although the psychological and the engineering school offer valuable contributions to the understanding of SA we believe SA can only be fully understood as a systems ergonomic phenomenon.

This is further highlighted in that the three schools give rise to differing approaches to support and design for SA. The psychological approach places the emphasis on the cognitive properties of SA and suggests design guidelines which counter the limitations of human cognition, such as limitations of memory and attention, while drawing on the cognitive mechanisms of schemata and mental models to counter these. This is exemplified in a study by McCarley, Wickens, Goh and Horrey (2002) who developed a computational model of SA to predict pilot errors. They report results that indicate success in predicting improved performance associated with display augmentations, particularly with regards to the effects of visibility, distraction and degraded information quality.

Designs aimed to support team SA has to a large extent focused on shared displays to support the development of shared SA. Endsley and Jones (2001) suggest using large screens that are viewable from around the room or across electronic information sharing devices such as the internet. This approach advocates using abstracted shared displays (Endsley and Jones (2001) where the information presented is the same to all team members. 
The engineering notion of SA gives rise to a new technology and interfaces which aim to contain all the SA relevant information for a specific task. Displays, such as computer screens, projected images and writing boards allow information to be present for all team members so that they may extract the information they need when they need it (Wears and Perry, 2007). For instance, DeMeis (1997) suggest that Ground Proximity Warning Systems provide SA information to help avoid controlled flight into terrain. Thus the technology alerts the operators of discrepancies between actual and desired system states to prompt the operators to act to re-establish equilibrium.

There are distinct similarities between the notion held by Endsley et al. (2003) that display design should directly present SA relevant information to individuals, or as in the case of shared displays to teams, and those held by the ergonomics approach. Although Endsley et al. (2003) considers the importance of the display as a vessel with which the individual is provided with awareness of a situation or is enabled to comprehend elements of a situation, whereas the engineering approach maintains that the awareness is entirely contained within the artefact regardless of whether there is an individual present or not, we cannot see a difference between the two stances on the design of displays since each focus on the display as vessel for the awareness material, and crucially, since neither consider the interaction between the individual and the artefact in producing SA.

In contrast to the views held by the psychological and engineering perspectives the distributed cognition theory advocates systems ergonomics design principles to support SA. The concept of distributed SA has significant implications for the design of complex systems (Salmon et al., 2009c). Rather than seek to support identical awareness of shared situational elements displays should support distinct but compatible SA requirements of different users and aid SA transactions among team members (Salmon et al., 2009c). Salmon et al. (2009b) suggest the provision of role-based interfaces, displays and tools that are designed around each user's distinct SA requirements. Displays and interfaces should present the SA information required by each user, and not contain information required by other roles and functions (Salmon et al., 2009b). A case study reported by Salmon et al. 
(2009b) suggests that this means providing customisable interfaces and role-based systems (Salmon et al., 2009b). An interesting example in this respect is the speed bug present in the cockpit in our analysis. The speed bug is used by both pilots; however, the use of it is different. The PNF use it to read and select the correct flap and slat settings while the PF use the speed bug setting to guide the point at which he slows the speed of the aircraft and descends it for landing. Neither pilot need to remember the speed the aircraft holds and in this way the speed bug removes a significant part of the pilot's workload. The cockpit was not designed with distribution of work in mind, however, it is clear that the equipment present has evolved over time (external speed bugs being used to indicate critical speeds is a case in point) to allow the pilots to offload certain mentally taxing tasks. Indeed, if we were to measure the pilots SA and include in this measure the speeds would not be within the individual's situation awareness. Because the cockpit as a system is constructed in this way remembering speeds is no longer a requirement for SA. In calling for a systems approach to designing for SA we call for an explicit consideration of the role of each member of a team along with the artefacts in their environment and consider that SA ought to be distributed between them. In so doing achieving the effect seen in the cockpit can happen without considerable evolution taking place. Salmon et al. (2009b) argue that this approaches utility lies in its output, in that it enables a description of the systems DSA in terms of content but also in terms of the relationships between them. Hence Salmon et al. (2009b) goes further than describing the pieces of information individuals need to know. Collaborative systems which allow information to be transmitted between agents and artefacts should be the focus of design. Achieving a good fit between a piece of equipment, such as a display, and the system in which it will be used receives less attention currently than the appearance of that display, designers should seek to establish a better balance here.

Similarly, Walker, Stanton, Salmon and Jenkins (2009b) report a study which found poor SA in a command and control team involved in a battle group planning task. They reasoned that the poor level of SA was attributable to a number of external artefacts which enabled knowledge to be contained 
in the world. As such it was not necessary for the team to remember specific elements of their planning which referred to for instance moves as these were represented externally to them (Walker et al., 2009b). Woods and Sarter (2010) present examples of technology which has created challenges for SA when they aimed to improve SA. By requiring the individual to keep track of yet more technologies the system is made increasingly more complex (Woods and Sarter, 2010). Instead, they suggest that design should be reframed in terms of how it can help people in their roles as problem holders (Woods and Sarter, 2010). This may mean as we have exemplified above, that certain artefacts take over the responsibility for certain parts of a task, such as remembering speed, to allow the individual to focus on their more important task of flying the aircraft. As a consequence, if designers were asked to make a cockpit which enhances SA of the pilots, assuming no prior knowledge of cockpit design, then the three level approach would not design speed bugs into the cockpit given that an SA requirement analysis would not reveal a need to remember speed for either pilot. It is our belief, however, that a systems ergonomics approach would reveal the need for external knowledge of speed and so design in speed bugs.

Stanton et al. (2010) assert that, as the idea of transactions suggest, information flows both ways. The process analysed here show how there is a constant flow of information around the system, from the PNF to the artefacts, from the artefacts to the PNF and from the PNF to the PF and so on. Thus, support for SA transactions need to be incorporated. One way to do so would be to map information together on displays (Salmon et al., 2008; 2009b; 2010). All of these suggestions indicate a considerable effort that need to be made by designers in understanding exactly what it is that users need to know, when they need to know it and what they need to know it for (Salmon et al., 2009b). This understanding needs to include what information should be presented, in what manner and to which elements of the overall work system (Salmon et al., 2009b).

As the above suggests the emphasis on SA as either contained entirely within the mind of an individual, as resident entirely within the world, or as an emergent, distributed, property gives rise to 
different views of how to support the development and maintenance of SA for teams. By taking a systems approach, however; as advocated by the distributed notion of SA, we need not neglect one perspective over another. Situating people within their environment and the context in which they operate in ensures that we can design systems which foster flow of information around the system, thereby supporting the transaction of SA and development of compatible SA. We believe this gives rise to agile and dynamic teams within complex systems.

The intention of this paper has been to analyse the process of descent and approach of an MD80 as described by Hutchins (1995a) from the perspectives of the three main schools of thought on SA. Our analysis has shown how the psychological and engineering schools emphasise distinct features of either the individual or the world as fundamental to the development of SA. These consequently give rise to design of either cognitively oriented or technology focused devices. Despite providing useful contributions to the understanding of SA and to the design of SA relevant artefacts and interfaces these approaches fall short of explaining the phenomenon completely. We therefore propose that the systems ergonomics approach, which combine the perspective of the individual and the world in considering the interaction between them present the most useful angle from which one can analyse and support the emergence of SA. 


\section{References}

Ackerman, R.K. (1998). New display advances brighten situational awareness picture. Combat Edge [Online]. Available from http://findarticles.com/ [Accessed 23 November 2009].

Artman, H. and C. Garbis (1998). Situation awareness as distributed cognition. In: T. Green, L. Bannon, C. Wareen and Buckley, eds. Cognition and cooperation. Proceedings of $9^{\text {th }}$ Conference of Cognitive Ergonomics, ECCE: Limerick, Ireland, p.151-156.

Artman, H. (2000). Team situation assessment and information distribution. Ergonomics 43(8), pp.1111-1128.

Banbury, S. P., D.G., Croft, W.J. Macken and D.M., Jones (2004). A cognitive streaming account of situation awareness. In S. Banbury and S. Tremblay (Eds.) A cognitive approach to situation awareness: Theory and application. pp.117-134.Hampshire: Ashgate.

Bedny, G. and D. Meister (1999). Theory of Activity and Situation Awareness. International Journal of Cognitive Ergonomics, 3 (1), pp.63-72.

Banks, A.P. and L.J. Millward (in press). Distributed Mental Models: Mental Models in Distributed Cognitive Systems. Journal of Mind and Behaviour.

Burns, C. M., G. Skraaning, G. A. Jamieson, N. Lau, J. Kwok, R. Welch and G. Andersen (2008). Evaluation of Ecological Interface Design for Nuclear Process Control: Situation Awareness Effect. Human Factors 50 (4), pp.663-679.

DeMeis, R. (1997). Improving pilot situation-awareness technology: key to reducing accident [Online]. Design News. Reed Business Information, Inc (US), 1997. Available from HighBeam Research: http://www.highbeam.com/doc/1G1-19600900.html [Accessed 23 November 2009].

Endsley, M. R. (1995) Toward a theory of situation awareness in dynamic systems. Human Factors, 37 (1), pp. 32-64. 
Endsley, M.R. (1999) Situation Awareness and Human Error: Designing to Support Human Performance. In Proceedings of the High Consequence Systems surety Conference. Albuquerque, NM, 1999.

Endsley, M.R. (2000). Theoretical Underpinnings of Situation Awareness: A Critical Review. In Endsley, M.R. and D.J. Garland (Eds.) (2000) Situation Awareness Analysis and Measurement. Mahwah, NJ: Lawrence Erlbaum Associates.

Endsley, M.R. and W.M. Jones (2001). A Model of Inter- and Intrateam Situational Awareness: Implications for Design, Training and Measurement. In McNeese, M., E. Salas and M.R. Endsley (Eds.) New Trends In Cooperative Activities: Understanding System Dynamics in Complex Environments. Santa Monica, CA: Human Factors and Ergonomics Society, pp.46-67.

Endsley, M. R., B. Boltè and D. G. Jones (2003) Designing for Situation Awareness: An Approach to User-Centred Design. London: Taylor \& Francis.

ESRI (2008). Public safety and homeland security situational awareness. White Paper, February 2008, New York: ESRI.

Jenkins, D.P., N.A. Stanton, P.M. Salmon, G.H. Walker and M.S. Young (2009).

Using cognitive work analysis to explore activity allocation within military domains. Ergonomics, vol 51(6), p.798-815.

Hollnagel, E. (2001). Extended cognition and the future of ergonomics. Theoretical Issues in Ergonomics Science, 2(3), p.309-356.

Hutchins, E. (1995a). How a Cockpit Remembers Its Speeds. Cognitive Sciecne 19, p.265-288.

Hutchins, E. (1995b). Cognition in the Wild. Cambridge, MA: The MIT Press.

Klein, G. (1998). Sources of Power: How People Make Decisions. Cambridge, MA: The MIT Press.

Masys, A.J. (2005). A systemic perspective of situation awareness: An analysis of the 2002 mid-air collision over Uberlingen, Germany. Disaster Prevention and Management, 14(4), p.548-557. 
McCarley, J.S., C.D. Wickens, J. Goh and W.J. Horrey (2002). A Computational Model of Attention/Situation Awareness. In Proceedings of the $46^{\text {th }}$ Annual Meeting of the Human Factors and Ergonomics Society. Santa Monica, Human Factors and Ergonomics Society, 2002. Niesser, U. (1976). Cognition and Reality: Principles and Implications for Cognitive Psychology. San Fransisco: Freeman.

Patrick, J. and N. James (2004). A Task-Oriented Perspective of Situation Awareness. In S. Banbury and S. Tremblay (Eds.) A cognitive approach to situation awareness: Theory and application, pp.61-81.Hampshire: Ashgate.

Patrick, J., N. James, A. Ahmed and P. Halliday (2006). Observational assessment of situation awareness, team differences and training implications. Ergonomics 49, pp.393-417.

Patrick, J., N. James, and A. Ahmed (2007). Awareness of control room teams. Le Travail Humain 70(1), pp.67-94.

Patrick, J. and P.L. Morgan (2010). Approaches to understanding, analysing and developing situation awareness. Theoretical Issues in Ergonomics Science, Vol 11 (1-2), p. 41-57.

Rousseau, R., S. Tremblay and R. Breton (2004) Defining and Modelling Situation Awareness: A Critical Review. In Banbury and Tremblay (eds.) A Cognitive Approach to Situation Awareness: Theory and Application. Aldershot: Ashgate Publishing Limited, pp.3-21.

Salas, E., C. Prince, D.P Baker and L. Schrestja (1995). Situation awareness in team performance: implications for measurement and training. Human Factors 37(1), pp.123-136.

Salmon, P.M., N.A. Stanton, G.H. Walker, C. Baber, D.P. Jenkins, R. McMaster and Young (2009a). What is really going on? Review of situation awareness models for individuals and teams. Theoretical Issues in Ergonomics Science, vol 9 (4) p. 297-323.

Salmon P.M., Stanton N.A., Walker G.H., Jenkins D.P., (2009b). "Distributed Situation Awareness." Ashgate Publishing Ltd, Farnham, UK, 250 pages.

Salmon, P.M., N.A. Stanton, G.H. Walker, D.P. Jenkins and L. Rafferty (2010). Is it 
really better to share? Distributed situation awareness and its implications for collaborative system design. Theoretical Issues in Ergonomics Science, 2010, Vol 11 (1-2), p 58-83.

Sarter, N.B. and D.D. Woods (1991). Situation awareness: A critical but ill-defined phenomenon. The International Journal of Aviation Psychology, 1(1), pp.45-57.

Smith, K. and P.A. Hancock (1995). Situation Awareness Is Adaptive, Externally Directed Consciousness. Human Factors, 37(1), p.137-148.

Stanton, N.A., P.M. Salmon, G.H. Walker, D.P. Jenkins (2010). Is situation awareness all in the mind? Theoretical Issues in Ergonomics Science, 2010, Vol. 11(1 \& 2), p.29-40.

Stanton, N. A., P.M. Salmon, G.H. Walker, D.P Jenkins (2009). Genotype and phenotype schema and their role in distributed situation awareness in collaborative systems. Theoretical Issues in Ergonomics Science. 10 (1), pp.43-68.

Stanton, N. A., R. Stewart, D. Harris, R. J. Houghton, C. Baber, R. McMaster, P.M. Salmon, G. Hoyle, G.H. Walker, M.S. Young, M. Linsell, R Dymott, and D. Green (2006). Distributed situational awareness in dynamic systems: theoretical development and application of an ergonomics methodology. Ergonomics, Vol 49, pp.1288-1311.

Stanton, N.A., P.M. Salmon, G.H. Walker, C. Baber, and D.P. Jenkins (2005). Human Factors Methods. A Practical Guide for Engineering and Design. Aldershot: Ashgate.

Sonnenwald, D. H. and L. G. Pierce. (2000). Information behaviour in dynamic group work contexts: interwoven situational awareness, dense social networks and contested collaboration in command and control. Information Processing and Management 36, pp.461-479.

Walker, G.H., N.A. Stanton, P.M. Salmon and D.P. Jenkins (2009a). A review of sociotechnical systems theory: a classic concept for new command and control paradigms. Theoretical Issues in Ergonomics Science, 9 (6), p. 479-500. 
Wears, R.L. and S.J. Perry (2007). Status boards in accident \& emergency departments: support for shared cognition. Theoretical Issues in Ergonomics Science, 8 (5), pp.371-380.

Woods, D.D. and N.B. Sarter (2010). Capturing the dynamics of attention control from individual to distributed system: the shape of models to come. Theoretical issues in Ergonomics Science, vol $11(1-2)$, p.7-28.

\begin{abstract}
About the authors
Ms Linda Sorensen is a research assistant and a doctoral student in Human Factors at the School of Civil Engineering and the Environment at the University of Southampton. Ms Sorensen gained a BSc in Psychology from the University of Oslo and an MSc in Organisational and Social Psychology from the London School of Economics and Political Science. Ms Sorensen spent two years in industry after graduating before joining the Human Factors team in the School of Civil Engineering.
\end{abstract}

Professor Neville Stanton holds a Chair in the Human Factors in the Transport Research Group within the School of Civil Engineering and the Environment at the University of Southampton. He has published over 150 peer-reviewed journal papers and 17 books on Human Factors and Ergonomics. In 1998 he was awarded the Institution of Electrical Engineers Divisional Premium Award for a coauthored paper on Engineering Psychology and System Safety. The Ergonomics Society awarded him the Otto Edholm medal in 2001 and The President's Medal in 2008 for his contribution to basic and applied ergonomics research. In 2007 The Royal Aeronautical Society awarded him the Hodgson Medal and Bronze Award with colleagues for their work on flight deck safety. Professor Stanton is an editor of the journal Ergonomics and on the editorial board of Theoretical Issues in Ergonomics Science. Professor Stanton is a Fellow and Chartered Psychologist registered with the British Psychological Society and the Health Professions Council, a Fellow of The Ergonomics Society and a member of the Institution of Engineering and Technology. He has a BSc (Hons) in Occupational 
Psychology from the University of Hull, an MPhil in Applied Psychology and a PhD in Human Factors from Aston University in Birmingham.

Adrian Banks is a lecturer in the Psychology department of the University of Surrey. The goal of his research is to understand complex reasoning and decision making in individuals and teams through basic and applied research. To do this he uses experimental methods and computational modelling, in particular the ACT-R cognitive architecture. Dr Banks gained a BSc in Psychology from St Andrews, an MSc in Occupational and Organisational Psychology and a PhD in Psychology both from the University of Surrey. Dr Banks is a Chartered Psychologist registered with the Health Professions Council and is a Fellow of the Higher Education Academy. 
Table 1: OSD key.

\begin{tabular}{|l|l|}
\hline & Process \\
\hline & Decision \\
\hline & Document \\
\hline & Manual input \\
\hline & Display \\
\hline & Connector \\
\hline & Direct data \\
\hline & \\
\hline & \\
\hline & \\
\hline
\end{tabular}




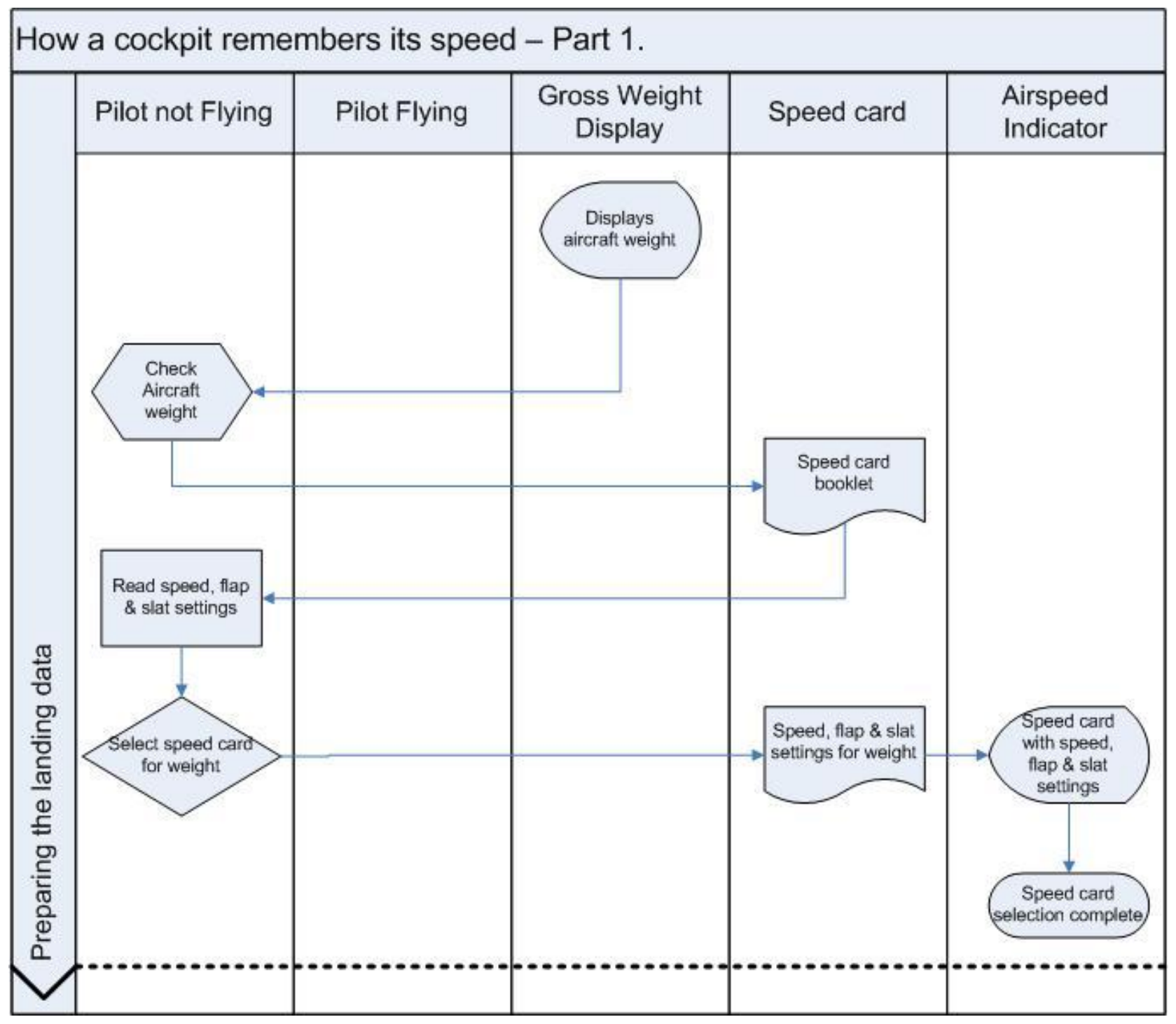

Figure 1: Distributed cognition in the cockpit, part 1, preparation of landing data. 


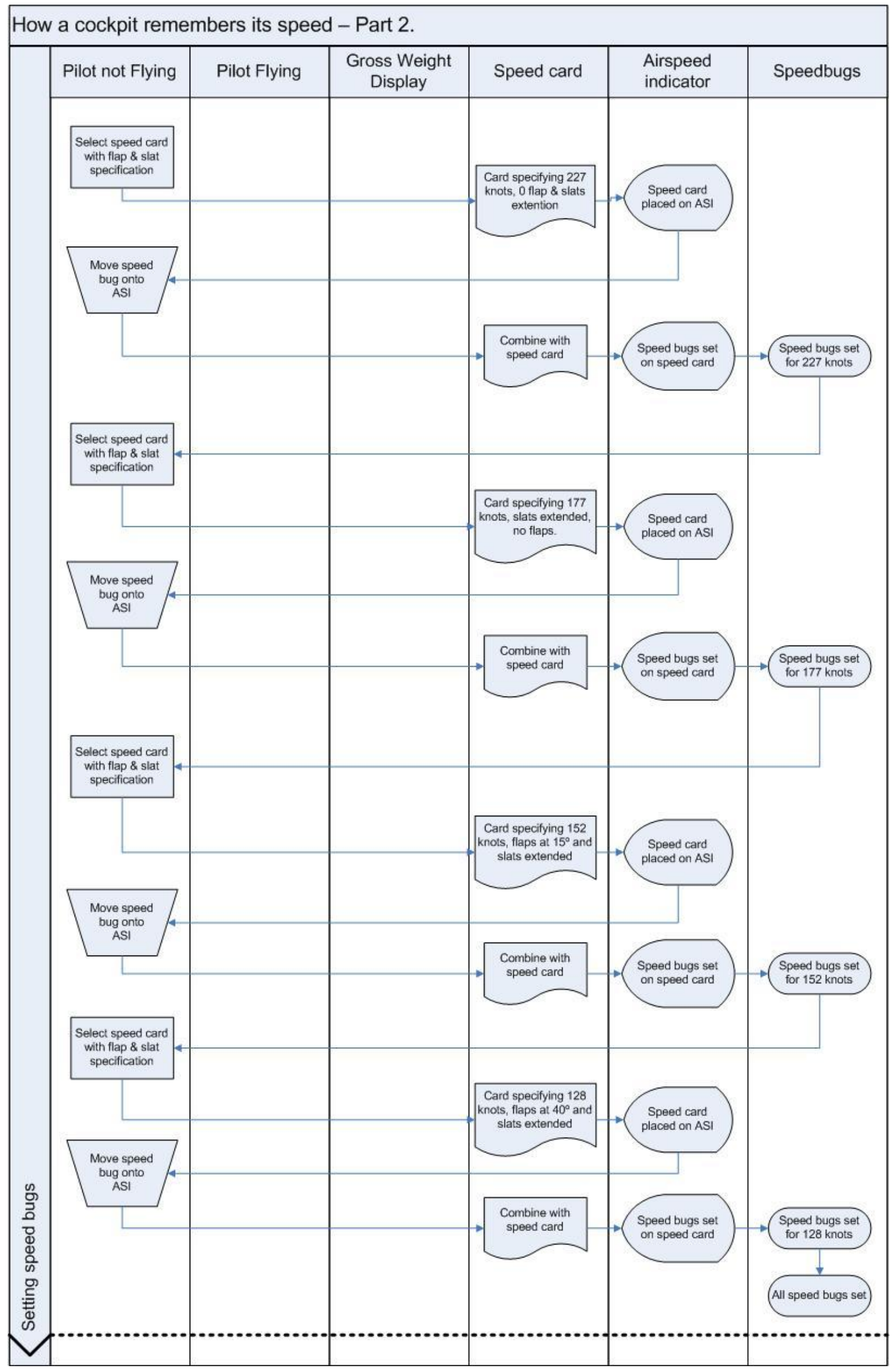

Figure 2: Distributed cognition in the cockpit, part 2, setting of speed bugs. 


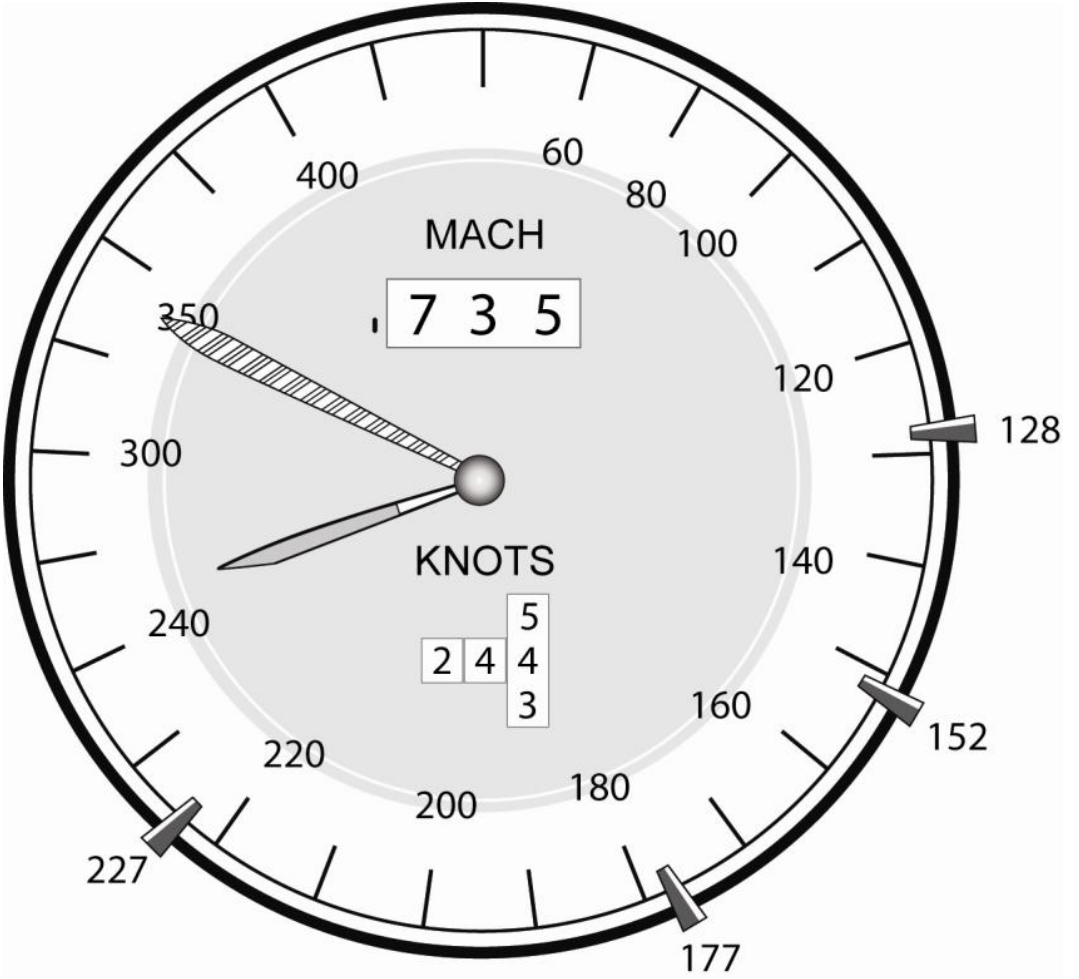

Figure 3: Speed bugs set on ASI, adapted from Hutchins (1995a). 


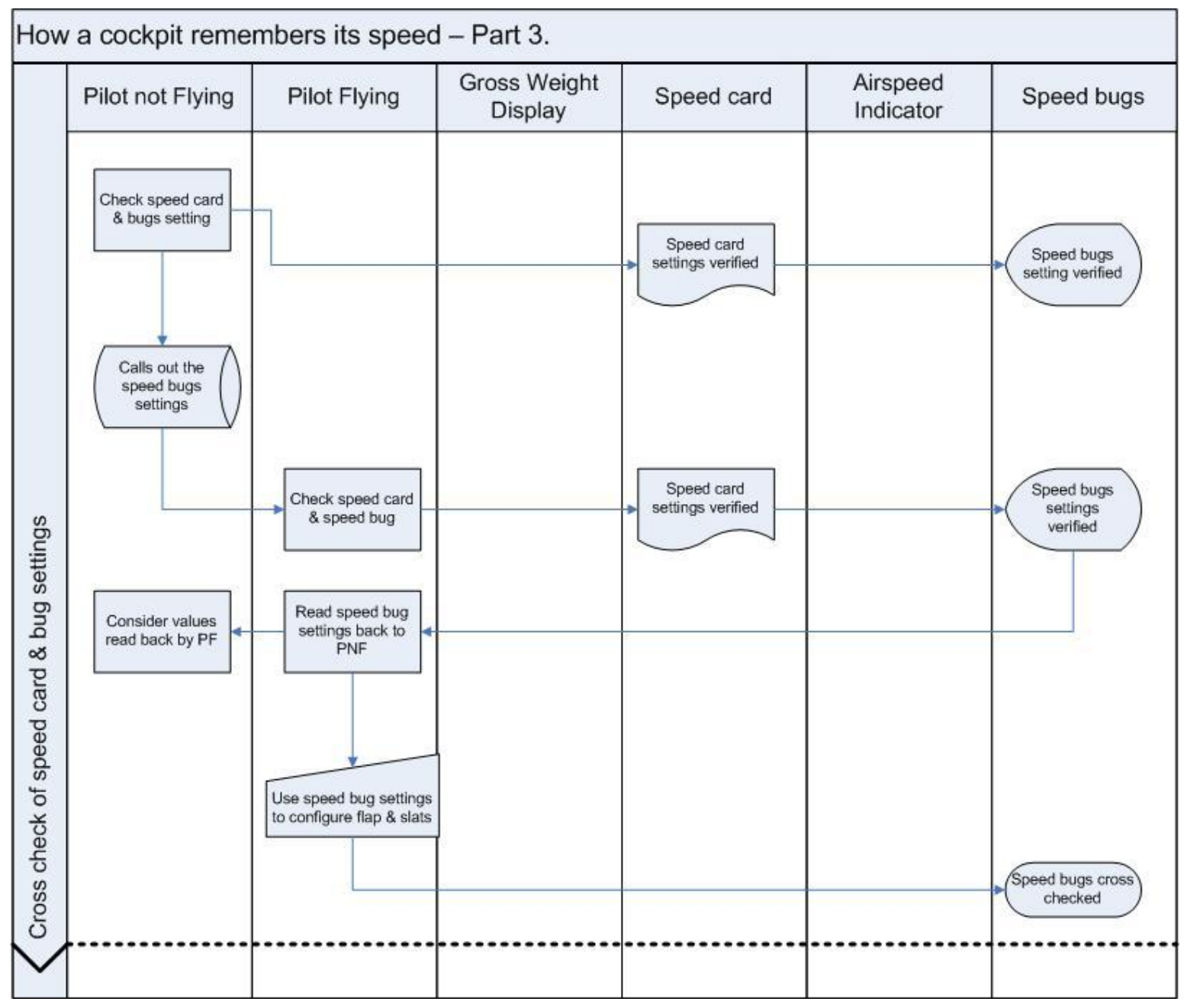

Figure 4: Distributed cognition in the cockpit, part 3, cross check of speed card and bug settings. 


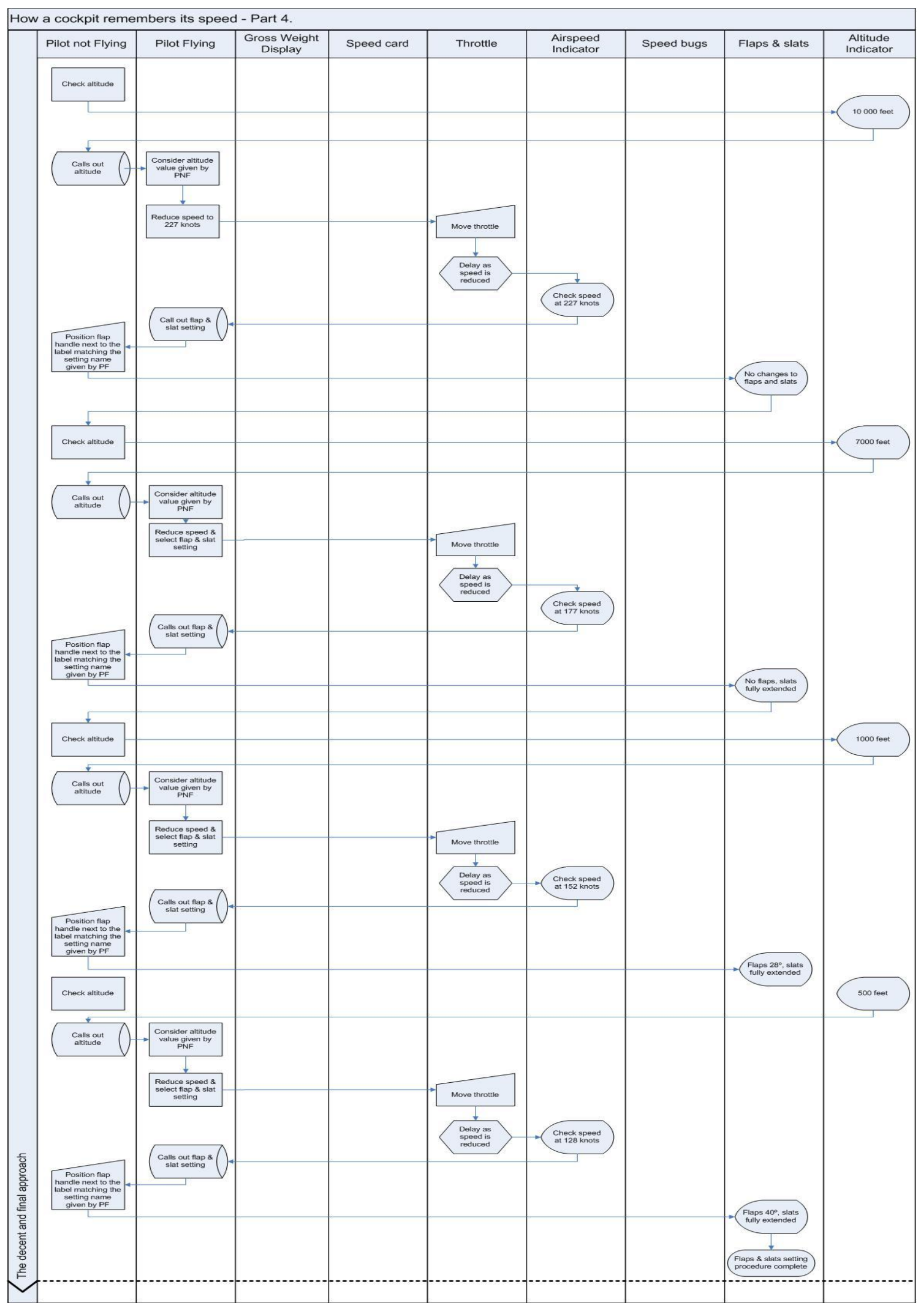

Figure 5: Distributed cognition in the cockpit, part 4, the descent and final approach. 
Table 2: Summary of analysis; illustrations of the product of analysis using either of the three theoretical frameworks.

\begin{tabular}{|c|c|c|c|}
\hline & Appr & ches to situation a & reness \\
\hline Phase of flight & Psychological & Engineering & System Ergonomics \\
\hline $\begin{array}{l}\text { Preparing the } \\
\text { landing data }\end{array}$ & $\begin{array}{l}\frac{\text { Level 1 SA }}{\text { PNF: Aircraft }} \\
\text { weight } \\
\frac{\text { Level 2 SA }}{\text { PNF: Selection of }} \\
\text { appropriate speed } \\
\text { card } \\
\text { Level 3 SA } \\
\text { PNF: Anticipation } \\
\text { of speed bugs } \\
\text { settings }\end{array}$ & 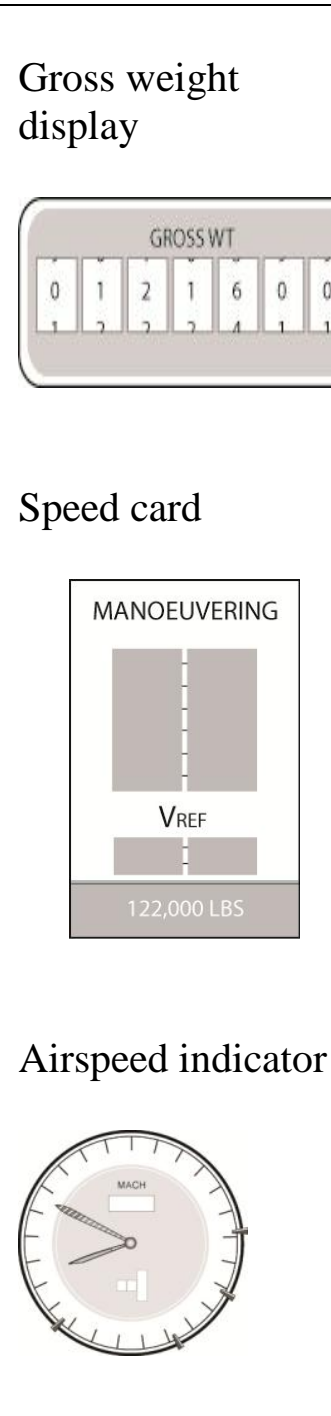 & $v$ \\
\hline
\end{tabular}


Table 3: Summary of analysis; illustrations of the product of analysis using either of the three theoretical frameworks.

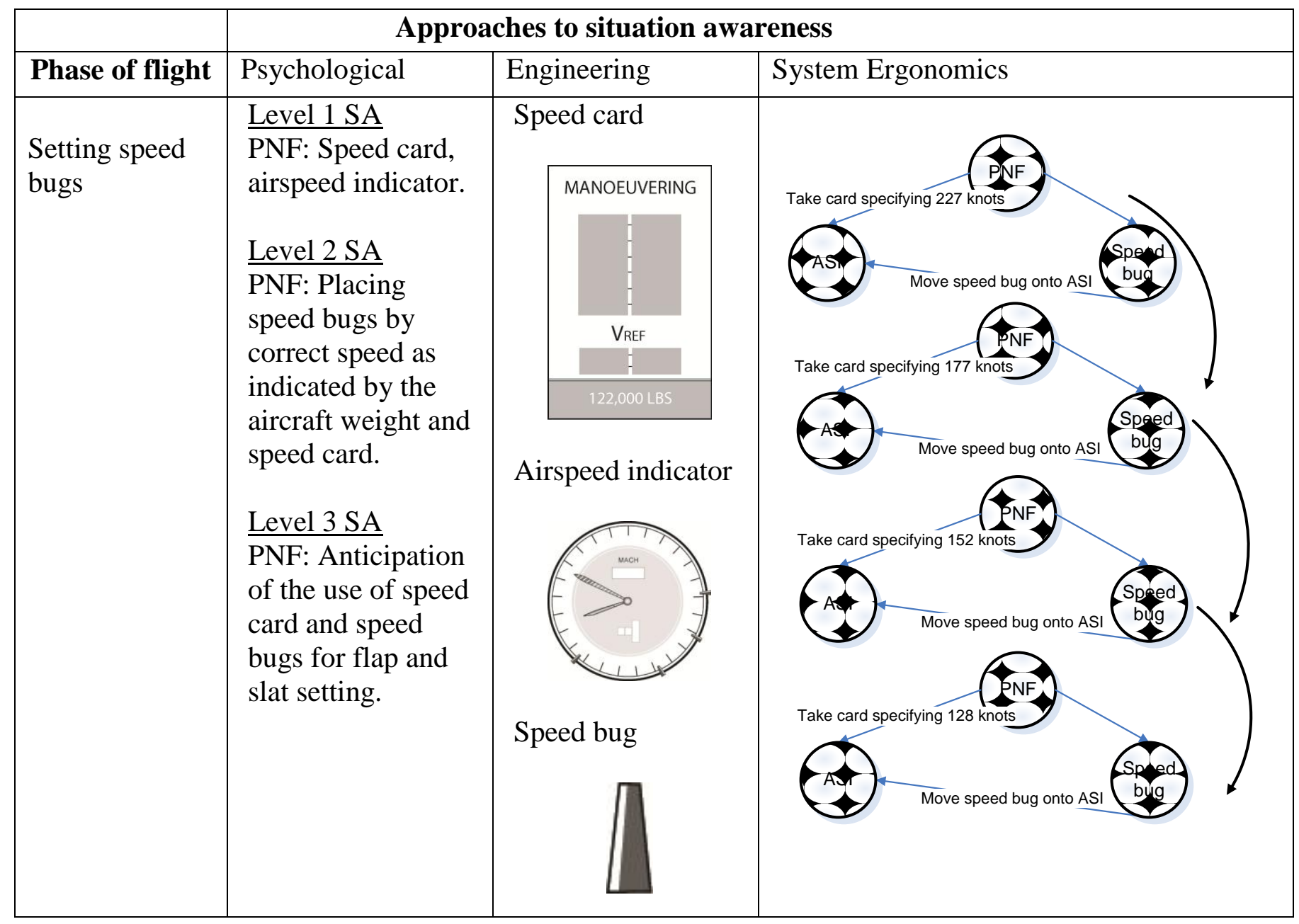


Table 4: Summary of analysis; illustrations of the product of analysis using either of the three theoretical frameworks.

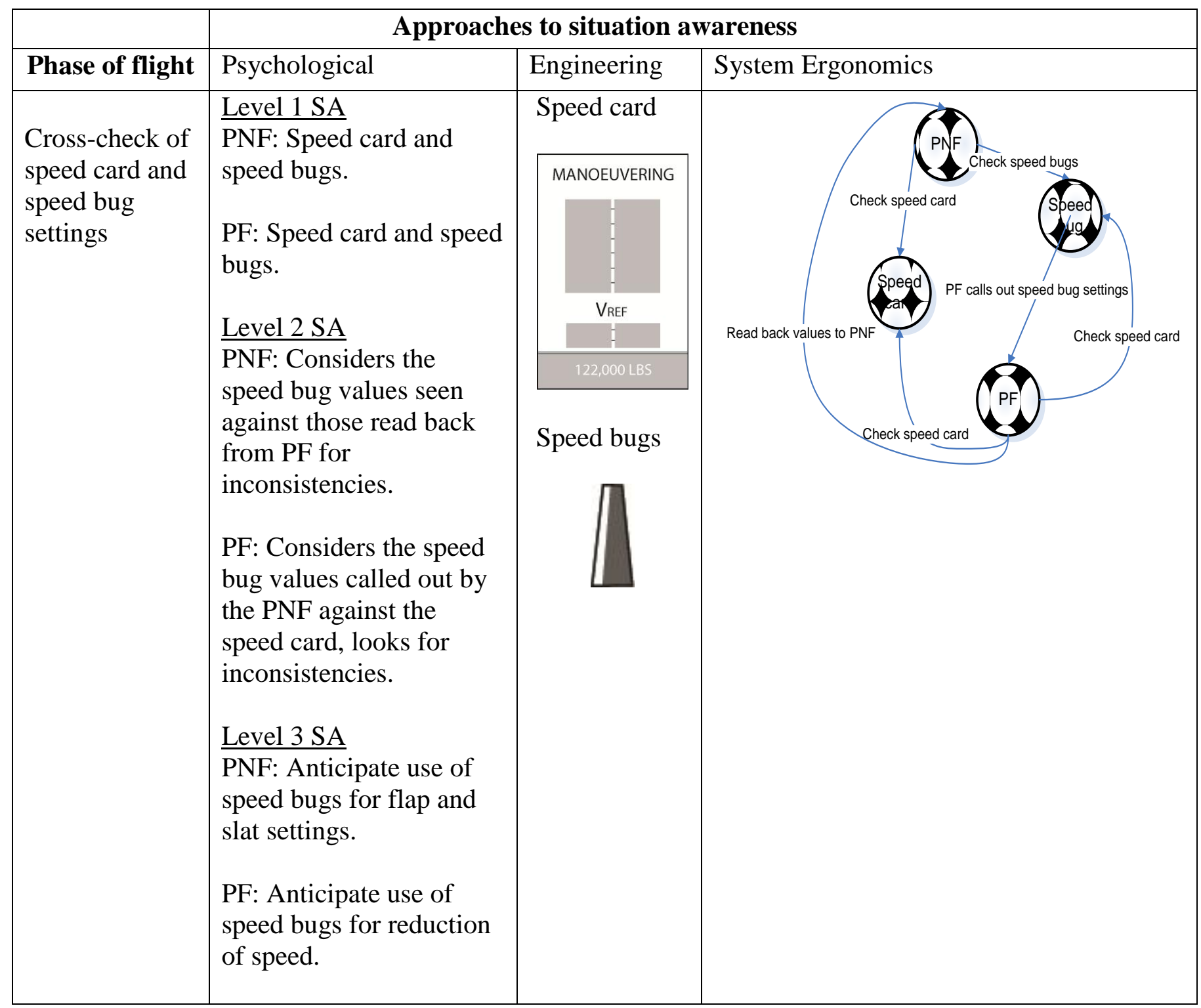


Table 5: Summary of analysis; illustrations of the product of analysis using either of the three theoretical frameworks.

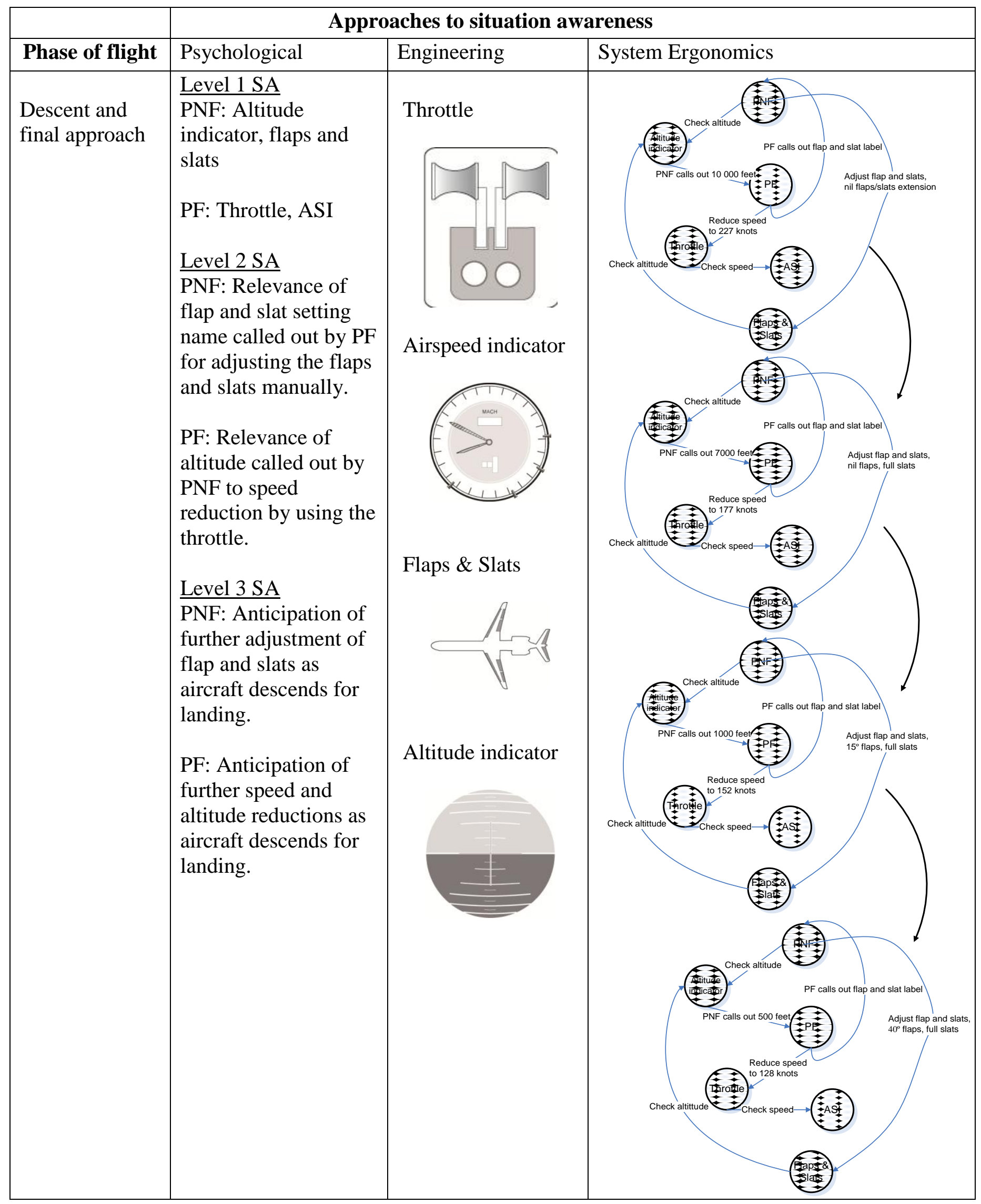




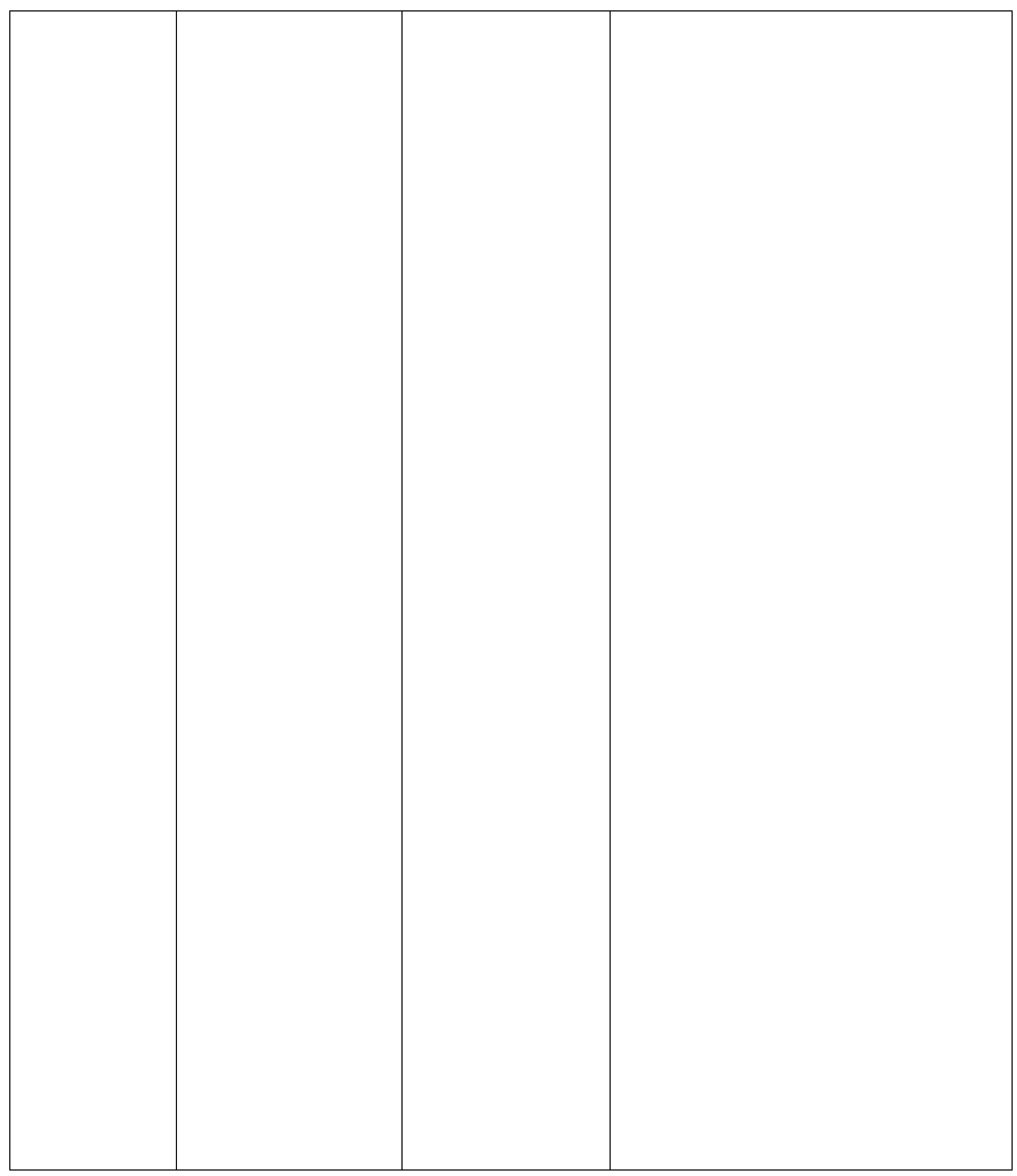

